condition. There was a large semicircular, dark, almost coppery-coloured patch, the epidermis being denuded, about three inches in diameter, extending from the angle of the mouth over the right cheek almost to the ear of the same side; it was dry, but had no scab upon it. There was a circular patch the size of a half-crown covered with a yellow eczematouslooking scab under the left eye, involving the lower eyelid. Both hands from the wrists downwards were of erythematous redness and completely denuded of epidermis, which had separated and hung downwards in a glove from the second phalanges of the fingers. There were also red, dry patches denuded of epidermis (circular, or some modification thereof) on each arm at the bend of the elbow. The general appear. ance of the hands and patches was as if the child had been severely scalded. but the denuded epidermis was quite white, and the serum clear like water. The history given me was that the child, said to have been previously healthy-and it was a fine, well-nourished one-had been brought from Stafford by train on Feb. 2nd, nine days previously, to a solitary house occupied by a shepherd and his family in a mountainous part of Wales. The mother had sent it to be nursed, and some tinned milk was sent with it and given for two days, when the child refused it, and fresh cow's milk was substituted. From this time the child seemed to be unwell and five days previously to being seen (i.e., on Feb. 6th) vomited and had a fit. After this the first patch appeared on the inside (bend) of the left elbow, being quickly succeeded by those on the face. The patches, which were in the early stage of erythematous redness, circular, or some modification thereof, in form, and not raised above the level of the surrounding skin, nor with any hardness of the base on the surrounding parts, appeared thus as I saw them. First, a minute area of skin the size of a pin's head became reddened and spread circularly and rapidly; almost simultaneously a blister appeared in its centre, spread over and to the extent of the red patch, and then burst, discharging a clear, water-like serum, the epidermis remaining wrinkled and folded. (In course of time, which is variable, the patch becomes of a deeper red hue, and the epidermis is denuded altogether.) Excepting in the one under the left eye, there was no appearance of a scab in any other of the patches. The spreading of a patch occurs so rapidly that in the course of three or four hours' time some of them will cover and denude a large extent of skin-from one to four inches in diameter. On Feb. 13th the child was still collapsed and in much the same condition as on Feb. 11th as regarded the face, hands, and arms, but the hands were of a darker red colour. There was a fresh circular patch the size of a halfpenny on the throat, over the thyroid. The ears were entirely denuded of epidermis, both in front and behind. When previously seen the legs were clear, but now both entire calves were denuded and gangrenous (dry and black) without much fetor. The first patch, I was informed, had appeared on these, but on the afternoon previously, Feb. 12th, the feet were clear, but there were some patches on the thighs in different stages. I was shown a patch on the inside of the right thigh, where the preliminary red area had appeared two hours previously. It was now the size of a penny, with the wrinkled epidermis lying folded upon it. The child was fearfully depressed, the slightest movement seeming to cause intense suffering; the teeth and mouth were dry and typhoid in appearance. The tongue had a thin white coating, as had the greater part of the cavity of the mouth. There was neither diarrhoea nor vomiting, but there was general congestion of both lungs, with accelerated breathing and feeble moaning, the voice nearly gone, the face pale, the eyes sunk, the skin cold, and the pulse but faintly perceptible. On Feb. 14 th the patient died at 5 A.M. Both hands became gangrenous from the wrists downwards on the previous evening. The patient had neither convulsions, diarrhœa, nor vomiting before death.

Upon inquiry I found that there had been a case of measles in the house a fortnight previously to the child's having come there. As I afterwards had four cases at the town dispensary in which the acute pemphigus was associated with aberrant, almost suppressed, measles, I judged this case to be of the same nature. (It will be seen by this that my opinion at the time coincided with Dr. Webber's that "it is not unusual in some of the exanthemata and may suggest the possibility of an alliance in nature with these diseases.") At first, however, I imagined that the condition might bave been contracted from a disease called the "strike" (a kind of embolic or thrombotic gangrene, rapidly fatal, which occurs in young cattle and focks), which was at the time very prevalent amongst, and fatal to, the flocks herded by the shepherd in whose house the illness occurred and who had flayed many of the sheep; this idea was, however, dispelled upon subsequently seeing the other cases at the dispensary. I have not seen a similar case since. I am, Sirs, yours truly,

Frensham, Farnham, March 5th, 1891 .

E. Robinson, M.D. Edin.

LOCAL GOVERNMENT ACT, 1894: ARE DISTRICT MEDICAL OFFICERS QUALIFIED

TO BE ELECTED MEMBERS OF A PARISH COUNCIL?

To the Eaitors of THE LANCET.

SIRS, - There must be many medical men living in rural parishes and holding union appointments to whom this question is of some importance. As everyone has not seen the Act, I will quote the parts of the clause relating to the matter. "46. - 1. A person shall be dis qualified for being elected or being a member or chairman of a council of a parish or of a district other than a borough or of a board of guardians if he(d) holds any paid office under the parish council or district council or board of guardians as the case may be ; or $(e)$ is concerned in any bargain or contract entered into with the council or board or participates in the profit of any such bargain or contract or of any work done under the authority of the council or board. 3. Where a person who is a parish councillor or is a candidate for election as a parish councillor is concerned in any such bargain or contract or participates in any such profit as would disqualify him from being a. parish councillor, the disqualification may be removed by the county council if they are of opinion that such removal will be beneficial to the parish."

The majority, I have no doubt, would on reading this come to the conclusion that paid officers of a board of guardians could not become candidates for a parish council unless the county council saw fit to remove the disqualification. In both conclusions I think the majority would be wrong, for a county council has only power to remove a disqualification under $(e)$ and not under $(d)$. I do not, however, believe that they are disqualified, and to make this plain I will condense the clause thus. A person may not be a parish councillor, a district councillor, or a guardian if he holds any paid office under the parish council, or district council, or board of guardians, as the case may be. These last five words, "as the case may be," can only mean respectively, therefore, that unless a person was paid by the parish council he would not be disqualified. I am, Sirs, yours truly,

Gillingham, Dorset, March 17th.

T. Woods.

\section{ABDOMINAL SEOTION FOR RUPTURED GASTRIC ULCER.}

To the Elditors of THE LANCET.

SrRS, - In your account of the discussion at the Roya Medical and Chirurgical Society on Mr. Morse's case certain remarks of mine are so placed as to convey a meaning different. from what my language did convey, and from my views. In spealsing of flushing out the peritoneal cavity with warm distilled water I am represented as saying that the "water, if warm, served to abolish the symptoms of collapse; the best tem. perature was $112^{\circ} \mathrm{F}$.," the fact being that I detailed one case of very marked and sudden collapse, in which I revived the patient by the use of water at that temperature; it was used rapidly and only for a few seconds. I by no means propose or could give the sanction of my name to using such very warm water under usual circumstances or in slighter degrees of collapse, and still less to its use in the ordinary flushing out of the peritoneum (which may be rather prolonged) necessary after laparotomy for some forms of disease.

I am, Sirs, yours truly,

Wimpole-street, March 19th, 1891. RICHARD BARWELI.

\section{LIVERPOOL.}

(From oUR OWN CoRRESPONDENT.)

\section{City Coroner's Inquests in 1893.}

THE report of the Liverpool head constable for the year 1893 gives, among other interesting details, a return of the 